\title{
Institutionalizing Love: The Nuniaq-ing Custom among Alaskan Iñupiat
}

\author{
JULIE E. SPROTT ${ }^{1}$
}

(Received 9 April 1998; accepted in revised form 16 October 1998)

\begin{abstract}
Nuniaq-ing young children is a distinctive Iñupiaq childrearing custom that survives to this day. It concerns a kind of stereotyped cooing and singsong phrases directed by adults to infants and young children, and it appears to cement ties of particular kin to particular children. For example, parents use terms denoting the possessive form, panii "my daughter" and igñii "imy son," to mark a special closeness to one child or another. Naming practices also have significant bearing on applications of the custom. Though seemingly trivial and largely playful on the surface, nuniaq-ing serves to lay the foundation for forging affectionate relationships throughout the life span.
\end{abstract}

Key words: Alaskan Eskimo, Iñupiat, Northwest Arctic, childrearing, childrearing customs, naming practices, kinship, child indulgence, family relationships

RÉSUMÉ. Parler nuniaq avec les petits est une coutume d'éducation des enfants bien particulière aux individus parlant l'iñupik, et cette coutume survit encore de nos jours. Elle consiste en une sorte de roucoulement stéréotypé et d'expressions chantonnées qu'adressent les adultes aux bébés et aux jeunes enfants. Cette coutume semble cimenter des liens d'un adulte apparenté à des enfants particuliers. Par exemple, les parents emploient les termes qui reflètent la forme possessive, panii $\eta$ (ma fille) et ig̃ñii (mon fils), pour souligner qu'ils sont particulièrement attachés à un enfant ou à un autre. La façon d'attribuer un nom a également d'importantes conséquences sur les applications de la coutume. Même si parler nuniaq peut sembler au premier abord une activité de peu d'importance qui tient largement de la taquinerie, cette coutume sert de base pour créer des liens d'affection qui durent toute la vie.

Mots clés: Esquimau de l'Alaska, iñupik, Arctique du Nord-Ouest, coutumes d'éducation des enfants, attribution d'un nom, liens $\mathrm{du}$ sang, douceur avec les enfants, liens familiaux

Traduit pour la revue Arctic par Nésida Loyer.

\section{INTRODUCTION}

Surviving in an age marked by massive acculturative pressures on Alaska Native cultures is the Iñupiaq custom of nuniaq-ing of children. I learned about it while engaged in more than 18 months of fieldwork starting in the fall of 1995 in Noorvik (Fig.1), a village in the Northwest Arctic Borough (NAB). In essence, nuniaq-ing consists of a ritualized type of cooing, name alliteration, or a stereotypic kin term, or a combination, delivered affectionately to young children by close family members, usually parents and grandparents. Although words used by the relatives when nuniaq-ing might include nonsense syllables, parents, for example, are most likely to employ terms such as the possessives igñii "my son" or panii "my daughter" to indicate that the child "belongs" to them. By so doing, they verbalize their kinship tie and simultaneously demonstrate emotional connection to the child.

On the surface, the custom appears fairly straightforward. However, nuniaq-ing has complex interrelationships with the kinship system and traditional naming practices, producing consequences that extend far beyond childhood. One goal of my research on nuniaq-ing con- cerned the issue of culture change in rearing customs. Was there evidence over several generations of continuity or waning of this aspect of Eskimo parenting ideas and behavior? Interestingly, little mention of the custom is found in the literature on Eskimos. The primary exceptions are Jean Briggs' (1970) work with the Utku of Canada and, more recently, a language socialization study of another Canadian Inuit group, reported by Crago et al. (1993). I suspect the lacuna on nuniaq-ing in Alaskan Eskimo literature exists because (a) it occurs largely in the private sphere, so that many outsiders haven't observed it; (b) fine-grained research is scant on Alaska Native childrearing in general; and (c) researchers have not been sensitized to its presence. A Noorvik resident told me that nuniaq-ing rarely occurs in front of non-family members because, as he reiterated, "If I did it in front of you, he [the child] would be embarrassed... and that's not right...because he won't like it later on... and it's usually done one-on-one." While visiting in another home, I completely missed the nuniaq-ing phrase the mother said to her youngest daughter as she entered the house. I had just broached the nuniaq topic with the father when he inserted, "Did you catch [what my wife said] when she came in?" She had spoken

${ }^{1}$ PO Box 113069, Anchorage, AK 99511-3069, U.S.A.; jsprott@gci.net

(C) The Arctic Institute of North America 


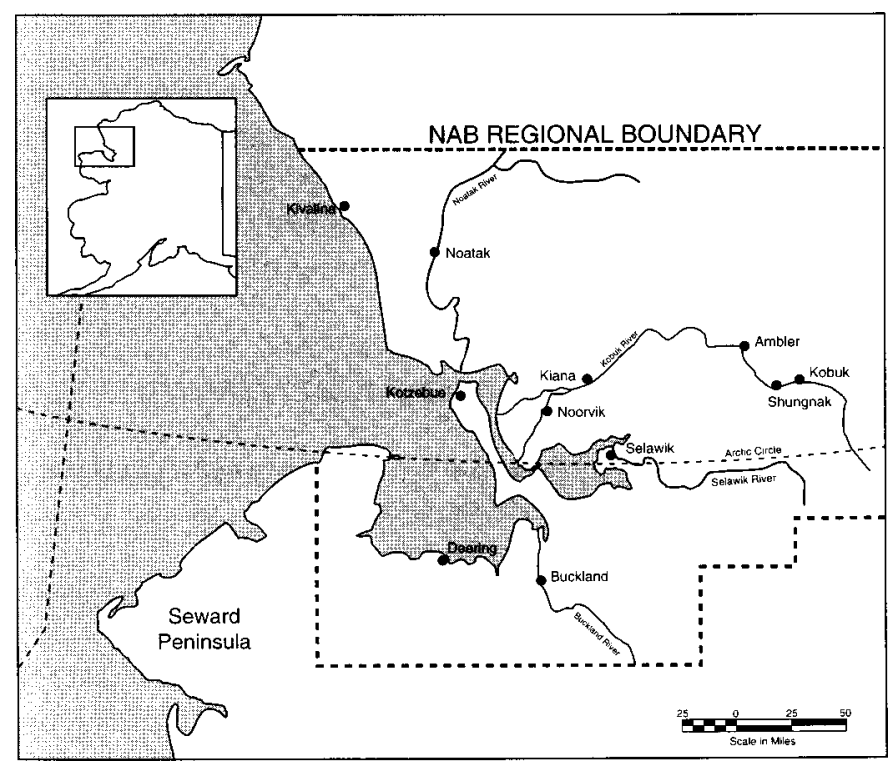

FIG. 1. Noorvik in relation to the Northwest Arctic Borough region

without particular emphasis and so softly that it had made no impression on me. Given these conditions, it is not surprising that my direct observations of nuniaq-ing were few. Thus, the data I draw upon are largely second-hand, obtained through my interviews with Iñupiat on the topic and from discussions about the custom provided by my Regional Advisory Committee (RAC; refer to the Acknowlegements section for their names and organizational affiliations).

The RAC was formed during the first-year pilot phase of the study in Kotzebue. Rachel Craig and I invited community leaders known to us who were well versed in Iñupiaq traditions and vocal advocates for the region's children and families. We asked them to evaluate every aspect of the projected instrumentation, a massive task involving critique of both quantitative tools for home and family assessment and qualitative interview guides, which featured questions focused on childhood and current childrearing beliefs and behaviors. Graciously and without much monetary compensation (a token $\$ 100$ ), the RAC members met for eight sessions, for a total of 17 hours of discussion time. I made notes during each meeting, then summarized their recommendations and distributed the minutes to them before the next scheduled session so that the group could make clarifications if necessary. It was the RAC who first brought the nuniaq/uๆa complex to my attention.

Before describing nuniaq-ing in more detail, I call to attention a traditional practice I dubbed "the rule of opposites," which bears directly on name bestowal and the show of affection to a child. One assigns a name by "lending something," the literal meaning of the Iñupiaq word atchiti (stem form, atchit- in Sun et al., 1979:151). Naming implies a potential close social relationship, either with the living older namesake or with his or her relatives, if that individual is deceased. Traditionally,
Inuit groups across the Arctic subscribed to the notion of the recycling of souls, and a hallmark of their reincarnation beliefs was the naming of a newborn after a recently deceased person (Mills, 1994). In Northwest Arctic villages, the namesake connection is referred to most commonly as having an atii $\eta$, the possessive form of the word for namesake, atiq.

At one of the meetings with the RAC, I was told that "in the old days" when a child was named for someone on one side of the family, the in-laws who stood on the other side regarded the child in a special way. That is, the child "belonged" to the side of the family that did not name him or her. The committee's explanation was echoed in Noorvik when a study participant said during an interview: "When you don't name a child of your own, you love them very much...because they're your in-law's name."

Complicating the search for "rules" in naming today is the fact that villagers have English given names in addition to their Iñupiaq names. One's first and middle English names and Iñupiaq name do not necessarily derive from a single referent. In a village-wide survey of naming practices in Noorvik spearheaded by Angie Newlin as an adjunct to the study, I found no match for the individual's English and Iñupiaq given names in the majority of 411 villagers polled. Additionally, more recently, parents tend to select English names for children that refer to no one in particular, or assign sons as "juniors." Nevertheless, because the RAC discussions so emphasized the "rule of opposites," I looked for its manifestation in my interview transcriptions. I had long interviews with 44 adult volunteers ( 22 parents and 22 extended family members) from 16 core families in Noorvik who were raising a child aged three to six years of age. Before addressing that issue, I first offer more on the content and function of nuniaq-ing.

\section{Nuniaq-ing}

In a nuniaq-ing episode, family members typically exaggerate words while making special facial and other physical motions, such as tickling, to generally tease the child and lavish special attention on him or her. Each relative uses a unique set of one or more nuniaq-ing expressions, called a nuniin, for each specific child as a way of showing that the child is special to him or her. The "cooing" by adults usually begins right from the birth of an infant and diminishes when the child is no longer considered a baby (usually around four or five years of age), although infrequent and abbreviated usage may extend well into adulthood. One nuniaqs in order to delight the child, to make the child's face light up, and for the toddler and preschooler, to cause the child to uๆa or display pleasure in being the center of attention. A child's u $7 a$ response may range from merely smiling or shrugging his or her shoulders in some fashion to approaching the speaker and giving a hug, dancing around, or "playing the baby," even to the extent of rolling or crawling on the floor and using baby talk. 
The RAC discussed at length the ritual-like aspects and various manifestations of nuniaq-ing, while cautioning me that families vary significantly in the frequency and extent of its use. Some rarely engage in the practice, while others go "the full length" in its expression. A listing of their points of discussion follows. I have inserted examples drawn from the Noorvik sample:

The older relative doing the nuniaq-ing is often physically close to the young child, perhaps holding the child on his or her lap.

Women are more likely than men to nuniaq a child, although this stereotype wasn't prominent among study families. When I asked the principal caregivers to name those who typically nuniaq-ed the focal child or who had done so in the past, they cited at least one male (usually a father or grandfather) for 12 of the children and a female for 15 children. My accounting included any reference to use by relatives of the specialized Iñupiaq terms of endear-

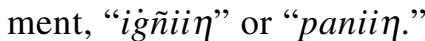

The nuniaq phrase is often multisyllabic nonsense, sounding "silly," and may rhyme with the child's name in a kind of ritualized baby talk. For example, a child with the name of Alex might be teased with this phrase: "Alex, Balex, Balex, Balex." A Noorvik grandmother provided a sample of her nuniaq-ing phrase to one grandson as: "sunulukali, sunuluk, sunuluka, sunuluk" and to another as

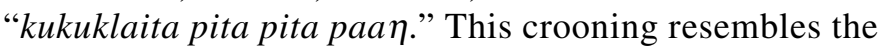
stereotyped nonsense phrase "kuchi-kuchi-coo" commonly addressed by English-speaking adults to infants. But unlike this phrase, the Iñupiaq counterpart is tailored to each specific child by each participating relative, and its use goes well beyond early infancy. There are exceptions to the practice of tailoring the cooing to each specific child. A grandfather described how his wife used a term of endearment with just about every youngster:

She used to nuniaq kids all the time... Her own kids, too. Even other kids. All the young ones that people have in their family...She always calls them "babe"...the youngest one in the family.

The younger the child, the more frequent the usage. Some relatives may nuniaq the child at almost every encounter, constantly reinforcing the signal of the adult's attachment.

Nuniaq-ing also is likely to be more extensive toward the last child in the family. This was evident in the report of one mother who recognized her desire to continue to "baby" her son. He was $31 / 2$ years old at the time of the interview:

I think I nuniaq too much and try to keep him as a baby because he's my last one, and I...think I'm doing that to him even right now. Try to let him be a baby, and not grow up to be a boy, a little boy. I try to keep him as a baby like and I...I don't want to do that. I want him to develop...I'm teaching him things all right, but...inside I still want to keep him as that little baby like this...holding him, cuddling him. I still pick him up like that and let him $u \eta a$, try to act like a baby.
The tone of the interaction is always loving, playful, or both. The strong sentiment associated with the practice was evident in one grandmother's story about her schoolaged grandchildren who had moved to another locale. She had heard that they had grown so accustomed to her cooing to them that after their move, they would mimic her and nuniaq each other. Hearing this delighted the grandmother, because it meant to her that they loved her and, as she put it, "They wanted to see me so bad!"

One of the unique names or phrases applied to the child by a relative may eventually become the child's nickname and then be used throughout this individual's lifetime. A Noorvik gentleman, for example, was given the Iñupiaq name of his maternal grandfather. Following his mother's lead, his family referred to him as "Dad Dad." Everyone in the village today refers to him by that nickname.

The urge to nuniaq a child is increased when the child has reached a milestone, accomplished something that made the parent proud, or behaved in an especially endearing way.

The name may be elaborated with other rhymes and songs, and some may be considered quite funny or hilarious. It is a way to experiment with language and to have fun in the process. For example, an elder stated that her mother's parents called her aaqaa $\eta$, which translates as "my stinky one." She added that "they hardly ever called us by our real names...they just called us by their nuniin."

The name or phrase may derive from something special that an adult or elder notices about a particular child, such as a physical characteristic like pretty eyes, or a turned-up nose (naqsik), or a personality trait or mannerism. A female interviewee said that a distant older relative always nuniaq-ed her with a phrase qaituyauraa, meaning that she was a quiet child who never complained or cried.

$U \eta a$ is the word that refers to the response by the child, which usually involves smiling and laughing. Points about the behavior are presented in the following list. Una behavior is quite variable, depending on the child. A father talked about his observations of the range of children's reactions to nuniaq-ing:

Some kids you... when I watch the... parents, they nuniaq the kid...and some of them [the children] will una so much, you know, that they'll roll on the floor, start rolling around, you know... but some of them...they'll just smile and...it's...two ways that they take it, I guess...I do that to mine... [and] they come and give me a hug.

A grandmother noted that her saying " $k u u-k u u n$ baby, kuu-kuun!" to her four-year-old grandson would induce him to start crawling on the floor like a baby.

The younger child who is nuniaq-ed will likely bask in the recognition of his or her special attributes, strengths, and small accomplishments and may repeat the behavior to receive more attention. An example of this was given by a father in describing his son's interaction when his grandmother nuniaqs him:

She does it usually when he does something that she is real proud of. You know... and then later on to get that 
same reaction out of him [means "her"], I can see that he will try to do it again in front of her... and repeat it, so he can get that same reaction from her.

Although the younger child is sometimes uncertain what to do and "acts like a baby," an older child on the other hand may feel embarrassed by being treated as a baby and may try to minimize the attention directed toward him or her. One mother described the standoff reaction from her five-year-old son:

Not, you know, it used to never really bother him when he was little bit younger...you know, the way [in a singsong voice] "Oh son, my son." [I'd] call him "papa" "cause he's named after my dad...And stuff like that. And now, he's getting a little bit older, and, he'll kind of [say] "Mom!"...kind of push you away and stuff.

\section{Practice of the Custom Elsewhere}

Nuniaq-ing among Iñupiat sounds very much like the behavior of relatives toward young children among the Utku Inuit of Canada depicted by Briggs (1985). The Utku word for a similar custom is niviuq, but niviuq in Iñupiaq carries a much different meaning. An RAC member warned me not to equate them, because that word in Iñupiaq has sexual connotations. Nevertheless, niviuq in Utku translates as "to wish or to arouse the wish to kiss or touch another affectionately" (Briggs, 1970:313). Briggs suggests that the term is applied more often to infants and children under four, the age when children first accomplish walking and talking, imitate adult behavior, and will perform on demand things that adults teach them. She states: "Utku consider that it is in the nature of a child to wish to elicit demonstrative attention" (Briggs, 1970:317). Briggs describes several characteristics similar to those I heard for nuniaq-ing. The demonstrativeness is highly patterned by characteristic cooing phrases (aqaq in Utku); a special endearment term used by each relative for the same child is usually said in the same tone of voice; and the endearment term may be used as substitute for a person's name even into adulthood.

The meaning of $u \eta a$ is closely matched in both languages (see Briggs, 1970; 1985). Briggs writes that uүa translates as "love" and refers to a dependent, possessive, needful emotion, most legitimate when a baby or child feels the need for his or her mother. She states further that the Utku perceive u $a$ as a form of suffering of the child, which a caring adult wishes to assuage. Thus the adult's response is to nallik, or to protect and nurture (nallik appears to be equivalent to the Iñupiaq verb nagligi-, "to pity another," according to Sun et al., 1979:191).

It is noteworthy that the Iñupiat typically reverse the sequence of interactions that Briggs describes for the Utku. Rather than taking $u \eta a$ as the antecedent behavior, as the Utku apparently do, the Northwest Arctic Eskimos

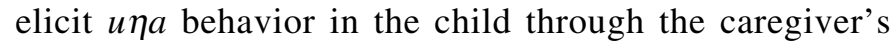
nuniaq-ing. And they do not view it as a kind of "pitiful" beckoning, as Briggs describes for the Utku.
Evidently for the Utku, game-like interactions are related to this ritualistic behavior between adults and children. Briggs (1990) believes that such interactions create an emotionally charged atmosphere where children learn the basic values of Eskimo culture. Part of the game playing involves asking the child, "Are you lovable?" This is a way to pose to the young child the meaning of caring and, in essence, to raise the threatening idea of how it might feel not to be cared for or loved. No one mentioned this type of game-like interaction among Iñupiat of the NANA region, nor did I witness this kind of behavior.

Cooing to infants, a feature in the nuniaq-ing complex, resembles maternal behavior described among the Great Whale River Eskimo (Honigmann and Honigmann, 1953:34): "Sometimes a mother will rhythmically repeat time after time a phrase containing the small one's name or its father's name." "Magic songs" and "petting songs" were sung to Ammassalik Eskimo children of Greenland until the age of eight or nine years, and these also had a kind of ritualized quality to them (Thalbitzer, 1941:599600). Burch (1975) mentions that grandparents in the Northwest Arctic would give pet names to their favorite grandchildren and call them by that nickname through the rest of their lives.

In a detailed study of language interactions of four Inuit children and their caregivers in Northern Quebec, Crago et al. (1993) wrote about the tradition of aqausiit. This tradition involves the chanting or singing of rhythmical verses made up by an adult and uttered to a specific infant to express love for the child, the same aqaq behavior described by Briggs. Although pointing out behavioral responses resembling $u \eta a$, they provided no term for it: "Children, it was reported, recognize their own chant and express pleasure physically by smiling, bouncing, and cooing in return" (Crago et al., 1993:212). Apparently, the tradition of aqaq has largely disappeared among these villagers, although adults, especially mothers, still employ nilliujuusiq, a kind of affectionate speech characterized by chanting or attaching "nonsense syllables onto sensible words and grammatical constructions" in addressing a child. However, nilliujuusiq apparently lacks the more ritualistic, repetitious qualities attributed to aqaq behavior.

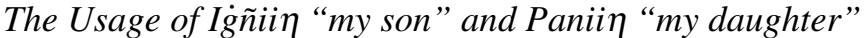

All but one child of 16 focal preschool children were reportedly nuniaq-ed by kin. When I asked the adults in the sample to describe their nuniaq-ing of these children, the common response was that they employed the genderspecific terms "igñii " "my son" (from the singular form for son, igñiq), "paniin" "my daughter" or "paniga," also "my daughter" (panik is the singular form for daughter. In English, it sounds like "bunik"). The -i $\eta$ possessive ending in Iñupiaq creates social emphasis that the child "belongs" to the speaker, and to no one else. It may or may not be associated with the child having a favored or special status, because in some families, both parents apply these 
terms to every son or daughter. One hears these words commonly spoken in public; they are not usually associated with demonstrative affection, nor does one see a child u $a$-ing in response.

The following excerpts from interviews illustrate the usage of these specialized terms. One mother remarked, for example, "What I say to my oldest ones, you know [is] igñii ... and paniin just to show them that I love them." I asked another mother how she nuniaq-ed her son and she replied, "I $\dot{g} \tilde{n} i i \eta$, my son...I love you. You're a good boy...Y You're with me."

The following statement was made by a father in response to my question about using the term igñiin:

If you say $i \dot{g} \tilde{n} i i \eta$, it's... saying how close the father is to the son...somehow I see it as... when I hear somebody say

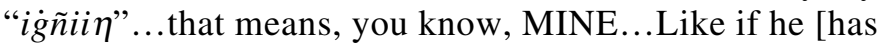
another son], then he call[s] his other son something else...And there's a difference here...you got to...close to him...when you still love both, but...this one is mine.

In the larger data set obtained on naming practices in the village, I noted that 118 respondents recalled that relatives had called them by these terms. Women remembered being called either panik and its shortened form pan or

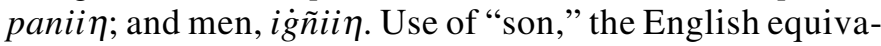
lent of $i \dot{g} \tilde{n} i q$, was also prevalent (reported by 22 men). In contrast, no women stated they had been called "daughter" in English. Not unexpectedly, relatives who used those terms were the respondents' parents; only ten represented some other category of family member.

Interestingly, the tone and affect associated with the Iñupiaq terms for son and daughter appear to be replicated in their use of "son" in English. In response to my question about who and how people nuniaq-ed her son, a mother answered:

I do, she [referring to her sister-in-law] does...Me, her, and my dad...She says, "Son, sooon [drawing out the vowel]. Where's my sooon?"...Me, same thing: "Son, soooon."

Among the study's primary interview sample of 44 adults, 27 stated that a parent (and perhaps also a grandparent or other close relative) routinely called them by the gender-specific designation of panii $\eta$ or $i \dot{g} \tilde{n} i i \eta$ when they were growing up. Thirteen of the 16 focal children were also called by the special daughter/son terms, demonstrating continuity of this usage to the youngest generation.

I also checked for the presence of the traditional "rule of opposites" in naming, because it implies special treatment of children. Of the 44 adults in the sample, only 21 were clear candidates for consideration, as they were named for one or more relatives on exclusively either the maternal or paternal side. The others were counted out because their English and Iñupiaq names reflected a mix of namesakes from both parent's families, or they weren't named for a relative $(n=11)$, or were unsure of their namesake's kinship affiliation, or had a parent who was non-Native $(n=12)$. During the interviews with these adults, I specifically asked about use of the terms of endearment, whether they were nuniaq-ed as children, and whether they regarded themselves as having been favored among their siblings during childhood. The analysis indicated that eight instances of the 21 conformed to the rule of opposites, in that the "other" parent showed them special attention or called them igñii or panii $\eta$ in contrast to an absence of such behavior by the parent from whose family the name derived.

Operation of the "rule of opposites" was imperceptible in relation to the newest generation, represented by the 16 focal children. Circumstances obviating its presence included the fact that three children had "mixed" names, from both parents' families, and four had a parent who was non-Native. Also, admission by parents about favoring specific children was rare compared to the prominent recollections of being favored in childhood in the interviews with the adults. To sum up, I found only a single example conforming to the traditional rule in the youngest generation.

\section{Namesake [atiq] Relationships}

Villagers typically call out "Hi, atii $\eta$ !" in greeting a namesake as they go about their daily affairs in the village. This term of endearment signals yet another potential relationship associated with nuniaq-ing a child. Bearing the name of a family member usually intensifies the child's tie to that individual or (if the atii $\eta$ is deceased) to those kin who cared deeply for that person. If the atiin is a relative, the tie seems to contradict the "rule of opposites," in that it implies that the child receives more attention from the kin group bestowing the name. I doubt that the concept of "possessiveness" implied by the rule of opposites means that the child is deprived of love from those who are not "possessors" (from the side of the family bestowing the name). Rather, I suppose that the atii $\eta$ relationship functions to ensure multiple avenues for expression of affection to children and to affirm connectedness.

Among the 44 adult volunteers from the core families in the study, 31 were named for people whose close relatives had been or were still residing in the village. Twenty-one of these indicated that their name had tangible social significance in childhood. The fact that 18 of these bore the Eskimo name of a grandparent, great-grandparent, aunt, or great aunt demonstrates that within-family bestowal of the name appeared to generate deeper emotional connection for individuals, although exceptions to that generalization abound, as the data also illustrate.

Bestowal of the name of someone outside the consanguineal/affinal kin group is often a sign of admiration, close friendship, or gratitude for assistance an individual provided the parents, among other things. For example, I asked a mother if the unrelated family gave any acknowledgment to her because she bore the Iñupiaq name of their deceased mother. Her response included the following remark:

Yeah, her daughter...her daughter calls me "mom" and...she makes me some stuff once in a while... she make me a beaver cap. 
An Elder answered my question about whether he remembered being nuniaq-ed by speaking of the association with his atiin's family:

Iiiii [Yes], yeah, these old people always [did nuniaq], because my...I was named after this man, their uncle. He's a nice man... and he likes his nieces and nephews and, after he's passed on. And I was named after him and they liked me. [JS then asked how they showed this affection] Oh they show me, I mean, good...they treat me good... and sometimes they give me [things].

Thirteen of the adults remembered being called by an endearment term "as if" they were the referent adult whose name they bore, a mother, father, aunt, etc. Almost always these designations were gender-matched. In one of the cases where this was not true, the participant said how much she didn't like being called the equivalent of "grandfather."

In the Arctic literature is found the idea that children named for their deceased grandparents were allowed to get away with just about anything (Stefansson, 1913; Thalbitzer, 1941). During life history interviews, I routinely asked whether the participant felt that his or her parents had favored any of the children. I then looked through the data to see if the 13 adults who were hailed "as if" a deceased relative had enjoyed favored status in the family compared to siblings. Indeed, 11 of the 13 remarked that they had been favored by one of their parents. (The 12 others who stated that they had been favored did not have such a kinship label.) Whether the 11 were "spoiled rotten" by the favoring parent could not be ascertained from their comments, although some did admit that they "got their way" more often than did their brothers and sisters, or that perhaps, things evened out because the other parent favored another sibling anyway. In discussing the impact of favoritism, however, the sample adults in general spoke against the practice, suggesting that it created much resentment among unfavored siblings, and many vowed not to replicate that behavior in their own parenting. I suspect that is the reason I found so little evidence for favoritism toward children in the 16 focal families (and the majority of households contained an average of three children).

I also wanted to learn how participants felt as children when called by a parent or grandparent term, to evaluate tangentially the presence of traditional reincarnation beliefs. In response to my question about how it felt to be addressed as aana "grandmother" or taata "grandfather" or as "mother" or "dad", sample adults said that parents calling them by those terms made them feel important and respected as individuals. Being so labeled also caused them to ponder the importance that the loved one had in the life of their own parent and what it meant to be loved in general. None of the 13 so termed in childhood gave any hint that they thought of themselves as being a reincarnate. One woman stated that as a child, when she acted in a certain way or showed certain preferences, her relatives might simply comment that her atii $\eta$ had enjoyed that activity or also had that preference.

Although for a large number of adult interviewees the atii $\eta$ relationship carried great significance in their growing up years, in contrast, atii relationships for the focal preschool children seemed much less salient. I cannot say with any assurance why this was so. Perhaps my impression stems from lack of observational data, or special behaviors associated with the namesake relationship had not yet been activated at the children's young age. Possibly, social changes in general have diminished its importance. Another possibility is that 10 of the children bore English and Iñupiaq names after kinsmen who were already deceased. These children lacked personal contact with the atii $\eta$, and perhaps the relatives didn't choose to emphasize the atii $\eta$ tie over their own connection to the child. Although eight could have been hailed as "papa," "mom," aana, taata, "aunt," or "uncle," in fact such terms were applied to only three children. Living namesakes of two children resided in another village, and they made no special efforts to maintain regular contact; however, an aunt of another child routinely sent presents back to her atiin. According to parents of three others whose naming honored a living adult (not counting boys named as "juniors") who lived in the village, two had not emphasized the atiin relationship separate from their kinship tie. The exception was an aunt who acknowledged the child with nuniaq-ing, hugs, and by calling her "atiin."

An important twist to the namesake phenomenon, too, is its potential influence on the child from adults in other villages. Status and attention may accrue to those children whose names recall highly respected deceased persons in the region. When such a child travels outside the village, those who knew the referent-named person come up to the child to acknowledge their love for the deceased and, in a sense, demonstrate transference of caring to the namesake. How children receive these kinds of greetings is unstudied, but it must make a significant impression on a young child.

\section{CONCLUSIONS}

Nuniaq-ing behavior, naming practices, and use of daughter/son terms are complexly interrelated. Traditionally, all were firmly embedded within the kinship system, but my data concerning the youngest generation of children implicate fraying of those interconnections. What once was an elaborate nuniaq/u a complex seems to have been reduced largely to the use of son/daughter terms; the rule of opposites has faded away, and demonstrations of affection specific to the namesake relationship have waned as well. I admit that absence of these "on-the-ground" behaviors may hinge on my choice of developmental age for the research, right at the time when nuniaq-ing behavior by adults reportedly diminishes. Having a limited sample of families in one village and focusing on only one child from each may have biased the results also. Broaderranging empirical research is needed to better appraise the nature and extent of culture change in these customs.

Despite what I perceive as cultural fragmentation in today's village environment, it is also abundantly evident 
that ideas about the nuniaq-ing custom remain strong. In my view, this distinctly Iñupiaq childrearing practice should be nourished. It can contribute to a child's self-esteem by signifying to the child that he or she is loved and is considered special. True, others might argue that the custom is simply one manifestation among many of the traditional warmth and indulgence traditionally given to children in Eskimo cultures (see general comments about this in Jenness, 1922; Honigmann and Honigmann, 1953; VanStone, 1962; Briggs, 1970; Coles, 1977; Lantis, 1980; Condon, 1987; Chance, 1990). But the nuniaq-ing custom does more than express affectionate behavior. Marking small accomplishments by warm teasing to the child indicates that the nuniaq-er is paying close attention to the child's behavior and appreciates the child's efforts. This kind of encouragement likely serves as a powerful positive behavioral reinforcer in addition to cementing social bonds. Imparted by the cooing behavior too is the meta-message that playfulness is worthy and important for its own sake and that human relationships are meant to be enjoyed. On the other hand, villagers also recognize that nuniaq-ing can be too much of a good thing. They related that praising a child can stunt development if it is so excessive that the child thinks he or she can do no wrong or feels no need to strive beyond his or her current level of achievement.

Finally, a superficial glance at the nuniaq custom may lead one to regard it as trivial and relatively insignificant when considered within the context of the entire life span; after all, its usage is largely confined to the first few years of life. However, I think that it is important precisely because of this early influence. Nuniaq-ing generates emotional electricity between adults and children that builds the foundation of warmth and caring in human relationships. Research on adult attachment and bonding suggests that individuals without the experience of being loved early in life are hampered in forging close bonds with others throughout life (On this complex topic, see Parkes et al., 1991; Colin, 1996; and Feeny and Noller, 1996.) Rather than merely quaint, nuniaq-ing is more appropriately apprehended as a brilliant Iñupiaq childrearing strategy that serves to institutionalize expressions of love toward the youngest generation, thereby setting the stage for perpetuating emotional warmth and sensitivity to others in the adults of the future.

\section{ACKNOWLEDGEMENTS}

This article is a revision of a paper presented at the Annual Meeting of the Alaska Anthropological Association in Anchorage, Alaska on 21 March 1998. It does not represent the views of any institution supporting the study or those of individuals other than the author. Funding for the research derived from a National Science Foundation Arctic Social Sciences grant awarded to the Northwest Arctic Borough (\#OPP-9218442) with the author as principal investigator. Special appreciation is extended to members of the Regional Advisory Committee for sharing their ideas about the nuniaq-ing custom. They are Linda Maamaq Joule, Northwest Arctic Borough, Assistant to the Mayor, who also teaches in Rural Development at Chukchi College; Ruth Tatqaviñ Sampson, Northwest Arctic Borough School District, Bilingual/Bicultural Education Program Coordinator; Susan Ti $\eta$ uk Adams White, Maniilaq Association, Director of Family Resources Program (and also for some time Harry Douglas of Ambler and Bea Mills from this organization); and Marie Kasa $\eta$ naaluk Greene, Vice President, NANA Regional Corporation. The other active member of the committee was Rachel Savigummuaq Craig, Iñupiaq Elder and coinvestigator on the grant.

\section{REFERENCES}

BRIGGS, J.L. 1970. Never in anger. Cambridge, Massachusetts: Harvard University Press.

1985. Socialization, family conflicts and responses to culture change among Canadian Inuit. Arctic Medical Research 40:40-52.

1990. Playwork as a tool in the socialization of an Inuit child. Arctic Medical Research 49:34-38.

BURCH, E.S. 1975. Eskimo kinsmen. St. Paul, Minnesota: West Publishing Co.

CHANCE, N.A. 1990. The Iñupiat and Arctic Alaska. Chicago, Illinois: Holt, Rinehart and Winston.

COLES, R. 1977. Children of Crisis. Vol. 4: Eskimos, Chicanos, Indians. Boston, Massachusetts: Little, Brown and Company.

COLIN, V.L. 1996. Human attachment. Philadelphia, Pennsylvania: Temple University Press.

CONDON, R.G. 1987. Inuit youth. New Brunswick, New Jersey: Rutgers University Press.

CRAGO, M.B., ANNAHATAK, B., and NINGIURUVIK, L. 1993. Changing patterns of language socialization in Inuit homes. Anthropology and Education Quarterly 24(3):205-223.

FEENEY, J., and NOLLER, P. 1996. Adult attachment. Thousand Oaks, California: Sage Publications.

HONIGMANN, I., and HONIGMANN, J. 1953. Child rearing patterns among the Great Whale River Eskimo. Anthropological Papers of the University of Alaska 2(1): $31-50$.

JENNESS, D. 1922. The life of the Copper Eskimos, Report of the Canadian Arctic Expedition, 1913 - 1918, vol. 12, part A. Ottawa: Edmund Cloutier.

LANTIS, M. 1980. The study of Alaska Eskimo childhood: Chance, Coles, Foulks, Hughes, Kleinfeld with suggestions for future research. Anthropological Papers of the University of Alaska, 19:2-14.

MILLS, A. 1994. Reincarnation belief among North American Indians and Inuit: Context, distribution, and variation. In: Mills, A., and Slobodin, R., eds. Amerindian rebirth: Reincarnation belief among North American Indians and Inuit. Toronto, Ontario: University of Toronto Press. 15-37.

PARKES, C.M., STEVENSON-HINDE, J., and MARRIS, P., eds. 1991. Attachment across the life cycle. London: Tavistock.

STEFANSSON, V. 1913. My life with the Eskimo. New York: Macmillan. 
SUN, S., DOUGLAS, F., GRAY, M., LOON, H., NEWLIN, A.,

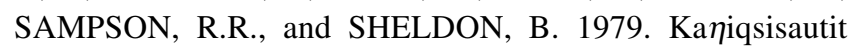
uqayusraġnikun. Kobuk Iñupiat junior dictionary. Anchorage, Alaska: Staff of the National Bilingual Materials Development Center, University of Alaska.
THALBITZER, W. 1941. Social customs and mutual aid. In: The Ammassalik Eskimo. Meddelelser om Grønland 40(4):565716.

VANSTONE, J.W. 1962. Point Hope: An Eskimo village in transition. Seattle, Washington: University of Washington Press. 